\begin{tabular}{|c|l|}
\hline Title & $\begin{array}{l}\text { Study on applicability of high durability friction grip joints with high } \\
\text { strength countersunk head bolts for steel bridge structures }\end{array}$ \\
\hline Author & TABATA, Akiko / YAMAGUCHI, Takashi \\
\hline Citation & $\begin{array}{l}\text { Memoirs of the Faculty of Engineering Osaka City University. } \\
\text { Vol.55, pp.43-50. }\end{array}$ \\
\hline Issue Date & $2014-12$ \\
\hline ISSN & $0078-6659$ \\
\hline Type & Departmental Bulletin Paper \\
\hline Textversion & Publisher \\
\hline Publisher & Graduate school of Engineering, Osaka City University \\
\hline Description & \\
\hline
\end{tabular}

Placed on: Osaka City University Repository

Placed on: Osaka City University Repository 


\title{
Study on applicability of high durability friction grip joints with high strength countersunk head bolts for steel bridge structures
}

\author{
Akiko TABATA* $^{*}$ and Takashi YAMAGUCHI ${ }^{* * *}$
}

(Received October 7, 2014)

\begin{abstract}
Synopsis
The authors focused on the high strength bolted friction grip joints with countersunk head bolts which can finish the surface of the connection plate flat smoothly and prevent from functional depression due to corrosion. Firstly we carried out Finite Element Analysis in order to evaluate the contact pressure of double shear connected friction joints with countersunk heads varying the angle of countersunk head. Secondly, we have compared the slip strength of the joints which has the optimum countersunk head angle with that of the joint with the normal high strength bolt through the standard slippage test considering variation of plate thickness and the yield strength of the base and splice plates. As a result, it has concluded that the slip strength of the joints with countersunk heads exceeds the required design slip strength which has specified in JSHB and that its slip coefficients is about $10 \%$ lower than that with normal head bolts.
\end{abstract}

KEYWORDS: Countersunk head bolt; contact pressure; slippage test; slip coefficient; slip to yield resistance ratio

\section{Introduction}

High strength bolted friction grip joints have been generally applied to connections of the steel structures from the viewpoint of economical rationality and reliability. The paint on the connection tends to deteriorate due to rust or shortage of the thickness of the paint at the corner edge. Because corrosion is accelerated at a place where drainage is poor and water is readily stagnant (See Pic.1). Moreover, asphalt pavement on the steel deck tends to be damaged by the existence of the bolt heads in it.

Therefore, the authors focused on the high strength bolted friction grip joints with countersunk head (See Pic.2) which can finish the surface of the splice plate flat smoothly and prevent from functional decline due to corrosion.

However joints with high strength countersunk head bolt has been already applied to the bearing type of the connection, there is almost no research paying attention to the friction grip joints with countersunk head bolts. When employing a friction grip joints with countersunk head bolts, it is necessary to verify the performance of the joint which can satisfy the required functions as a connection.

In this study, firstly we carried out FEA (Finite Element Analysis) varying the angle of countersunk head in order to evaluate the contact pressure of double shear connected friction joints with countersunk heads. Also, we have investigated the influence on load transferring mechanism by using countersunk head bolt for frictional joints. Secondly, we have compared the slip strength of the joints which has the optimum countersunk head angle with the normal high strength bolts through the standard slippage test focusing on variation of the plate thickness, the yield strength of the base and the splice plates.

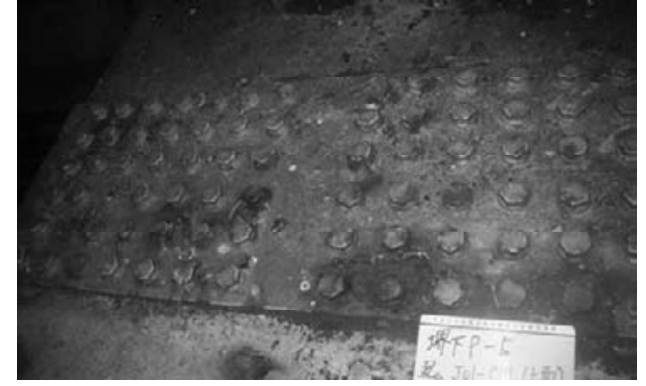

Pic.1 Corrosion damage of joint of steel pier

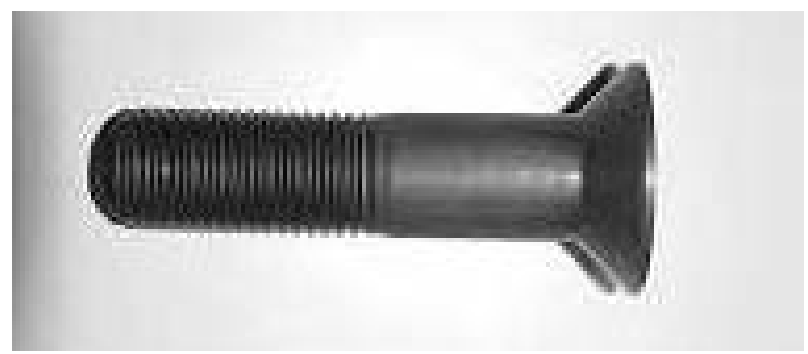

Pic.2 High strength countersunk head bolt

\footnotetext{
* Student, Doctor Course of Department of Urban Engineering

** Professor, Department of Urban Engineering
} 


\section{Mechanical Behavior from FEA \\ 2.1Outline of FEA and FE models}

The axisymmetric FEA was conducted by ABAQUS Standard 6.9[1]. Double shear connected joint are dealt with in the analysis. .

The countersunk head bolt for FEA is shown in Fig.1. In order to evaluate the slip strength with countersunk head bolts, the angle of countersunk head is changed as 60,70, 80,90 , and 110 degrees. For a comparison, the joint with the hexagon head bolt shown in Fig.2 is also dealt with. All of analytical cases in this analysis are tabulated in Fig. 1 and 2.

An example of the FEA model, CD-90 is shown in Fig.3. The thickness of the splice plate and the base plate is $16 \mathrm{~mm}$ and $32 \mathrm{~mm}$ respectively, and the length of the splice plate and the main plate is 50 and $70 \mathrm{~mm}$ respectively referring to the minimum spacing distance between bolts specified in Ref. [2] .Diameter of the bolt hole is $24.5 \mathrm{~mm}$, which is the standard value also specified in Ref. [2].

A contact boundary which can consider contact, friction, and separation is installed into the analytical surface between the splice and the base plate.

In order to clarify distribution of the contact pressure on the contact surface, the area where two surfaces are expected to be contact has fine mesh division. Friction coefficient for the contact surface is both 0.5 between the splice and the base plate, and also between the splice and countersunk bolt head surface. Design bolt axial force $205 \mathrm{kN}$ for F10T (M22) is installed into the bolt. The steel material is $\mathrm{SS} 400(\sigma \mathrm{y}=235 \mathrm{MPa})$, elastic modulus $\mathrm{E}$ is $2 \times 105 \mathrm{MPa}$, and poisson's ration is 0.3 . The FE model of the joint with hexagon head bolt (HD model) is also shown in Fig.4. Dimensions of the splice plate and the base plate are the same of CD series.

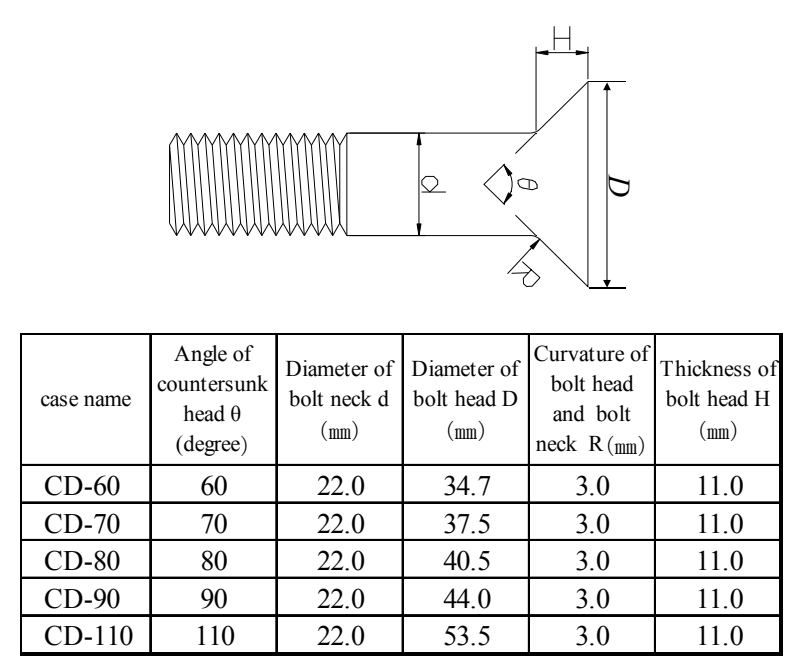

Fig.1: Countersunk head bolt

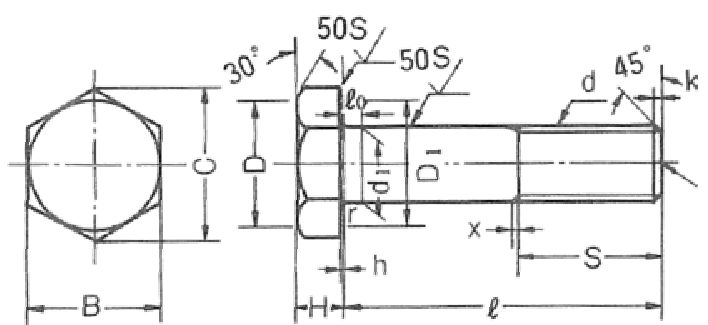

\begin{tabular}{|c|c|c|c|c|c|c|}
\hline case name & $\begin{array}{c}\text { Diameter } \\
\text { of bolt } \\
\text { neck } \\
\mathrm{d}_{\mathrm{l}}(\mathrm{mm})\end{array}$ & $\begin{array}{c}\text { Diameter } \\
\text { of bolt } \\
\text { head } \\
\mathrm{B}(\mathrm{mm})\end{array}$ & $\begin{array}{c}\text { Diameter } \\
\text { of bolt } \\
\text { head } \\
\mathrm{C}(\mathrm{mm})\end{array}$ & $\begin{array}{c}\text { Diameter } \\
\text { of bolt } \\
\text { head } \\
\mathrm{D}(\mathrm{mm})\end{array}$ & $\begin{array}{c}\text { Curvature } \\
\mathrm{R}(\mathrm{mm})\end{array}$ & $\begin{array}{c}\text { Thickness } \\
\text { of bolt } \\
\text { head } \\
\mathrm{H}(\mathrm{mm})\end{array}$ \\
\hline HD & 22.0 & 36.0 & 41.6 & 34.0 & 3.0 & 14.0 \\
\hline
\end{tabular}

Fig. 2: Hexagon head bolt

\subsection{Analytical results and discussions \\ 2.2.1 Contact pressure distribution}

Distribution of contact pressure at the contact surface between the splice and the base plate obtained from the FEA is shown in Fig.5. The vertical axis is contact pressure (MPa) and horizontal axis is the distance from the hole edge. As shown in Fig.5, it is found that high contact pressure over yield strength occurs around the hole edge in CD series comparing with that of HD. Its maximum value is that of CD-110. As the angle of countersunk head increase, contact pressure tends to become higher around the hole edge. On the other hands, the existence area of contact pressure of CD series is smaller than that of HD. The minimum case of the existence area of contact pressure is CD-110. Therefore, the FEA results indicate that contact pressure of $\mathrm{CD}$ series is higher than that of $\mathrm{HD}$ and is distributed in smaller area.

\subsubsection{Shear stress distribution}

Fig.6 shows the shear stress distribution on the contact surface. Arrow diagram of nodal force at the contact surface and the deformation are also shown in Fig.7. To understand deformation characteristics with ease, each displacement is multiplied by 100. It is understood from these two Figures that high shear stress occurs 
near the bolt hole edge due to the friction force by the local deformation of the splice plate.

\subsubsection{Maximum stress}

An example of stress contours of Von-Mises of CD-90 is depicted in Fig.8. High stress concentration over the yielding stress between the countersunk head and the shank is observed when the design bolt axial force, $205 \mathrm{kN}$ is applied. Maximum stresses of all cases when the design bolt axial force is applied are tabulated in Table 1. It is found that the maximum stress of CD series is higher than that of $\mathrm{HD}$, and that the case that the angle of countersunk head is 90 degrees shows lowest maximum stress. The reason is considered that the stress at the corner part between bolt shank and bolt head depends on the magnitude of the contact force along the perpendicular direction to the countersunk head and the distance from here to the applied point. It has concluded that the most suitable angle of the countersunk head is 90 degrees.

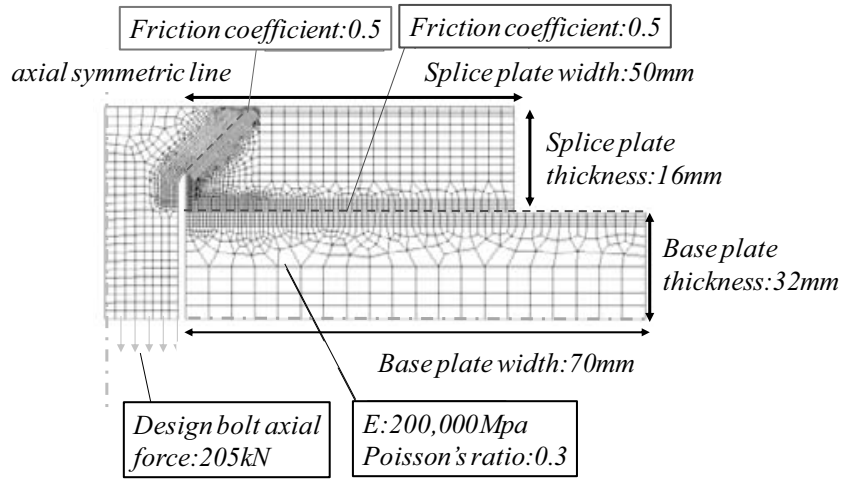

Fig.3: FEA model for CD-90

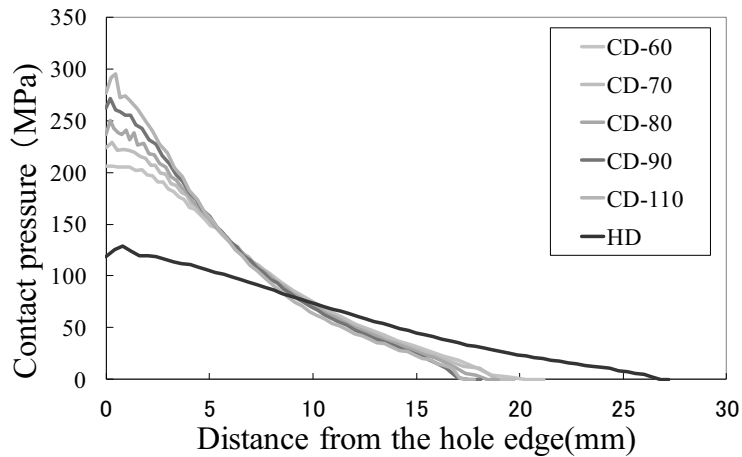

Fig.5: Contact pressure distribution on the contact surface

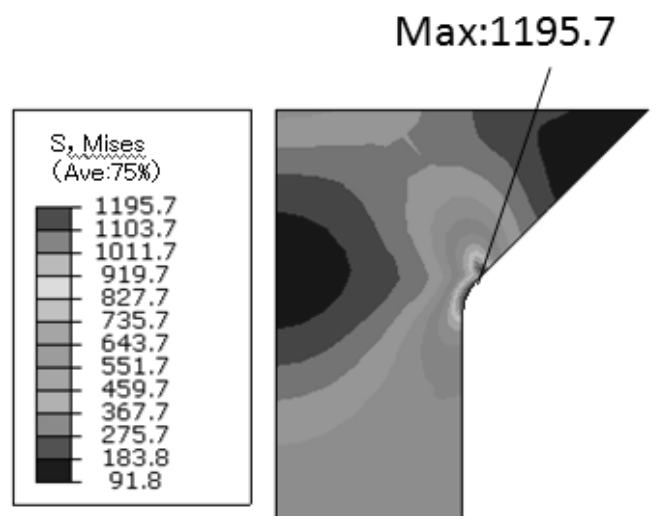

Fig.8: Stress contours of Mises(CD-90)

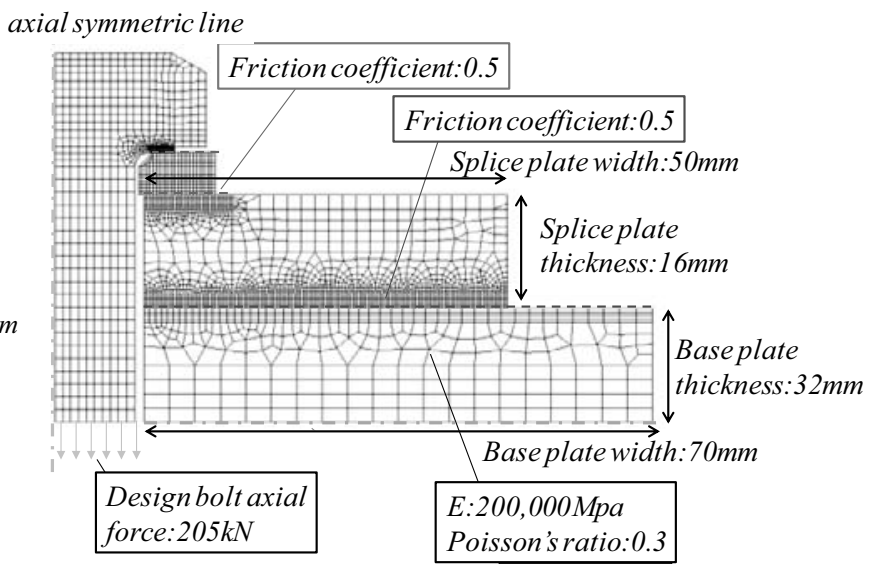

Fig.4: FEA model for HD

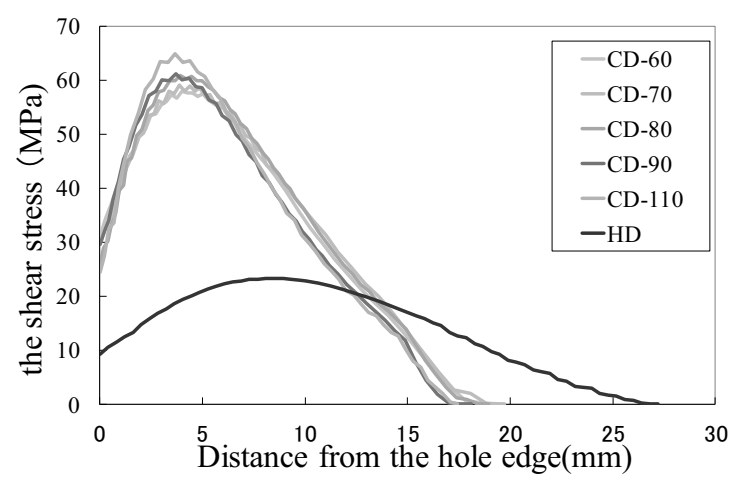

Fig.6: Shear stress distribution on the contact surface
Table 1: Maximum stress

\begin{tabular}{|c|c|}
\hline case name & $\begin{array}{c}\text { Maximum stress } \\
\left(\times 10^{3}, \mathrm{MPa}\right)\end{array}$ \\
\hline $\mathrm{CD}-60$ & 1.593 \\
\hline $\mathrm{CD}-70$ & 1.416 \\
\hline $\mathrm{CD}-80$ & 1.227 \\
\hline $\mathrm{CD}-90$ & 1.196 \\
\hline $\mathrm{CD}-110$ & 1.364 \\
\hline $\mathrm{HD}$ & 1.056 \\
\hline
\end{tabular}




\section{Slippage test}

\subsection{Outline of the slippage test and specimens}

In order to clarify the behaviour of friction joints with high strength countersunk head bolts for steel bridge structures, we have carried out the standard slippage test taking into account for steel material grade, slip to yield resistance ratio $\beta$, and the number of contact surface(double or single shear). Geometrical configurations of the specimens for the slippage test are shown in Fig.9. The structural parameters of the specimens are listed in Table 2. The angle of the countersunk head is fixed 90 degrees based of the analytical results described in chapter 2 and in Ref. [3]. Contact surface of the plates are painted by inorganic zinc-rich paint with more than $75 \mu \mathrm{m}$ thickness. Pic. 3 shows the specimen with the countersunk head bolts. Structural parameters in this experiment are explained in detail as follows;

a) Steel material grade (SS400, SM490) : Investigated is influence of local yielding around the bolt holes on the slip resistance.

b) Slip to yield resistance ratio $\beta$ : This is for clarification of the difference of mechanical behaviour between slipping type $(\beta<1.0)$ and yielding type $(\beta>1.0)$. $\beta \mathrm{d}$ (See Table 2$)$ is the ratio calculated by the friction coefficient $(0.5)$ and the nominal yield resistance. $\beta \mathrm{e}$ is the ratio calculated by the slip coefficient obtained from the experiment for the specimen of slipping type and yield stress obtained from the material test (See Table 3).

c) Number of the contact surface (double or single shear): Difference of behaviour caused by different number of the contact surface and eccentricity between the base and splice plate is investigated.

In the experiment, bolt axial force for the hexagon head bolt is measured by the strain gauge which glued on the bolt shank as shown in Pic.4. Bolt axial force for the countersunk head bolt is also measured from the strain gauges glued on the bolt head in consideration of preventing from stiffness decrease by the holes for the strain gauge wires as shown in Pic.4. The slippage test is executed by using universal testing machine $(1,000 \mathrm{kN})$ of Osaka City University. To clarify the slip behaviour with ease, fixed and slipped sides are set in advance by changing the bolt axial force. The bolts at fixed side are tightened with $10 \%$ higher of the design bolt axial force. Tensile load is applied until the major slip at the slipped side is observed. As shown in Fig.10, measured are relative displacements between the base plate and the splice plate, applied tensile load and bolt axial forces. In this experiment, the definition of slip occurrence is when the relative displacement at $\delta 3$ becomes $0.2 \mathrm{~mm}$ in accordance with the specification of Architectural Institute of Japan [4].

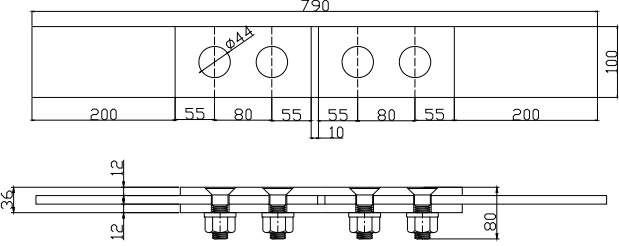

(a) CD-12M12S, CD-12M12M

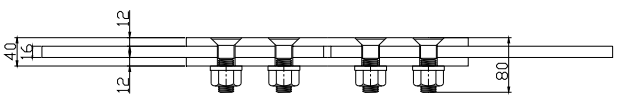

(b) CD-16M12M

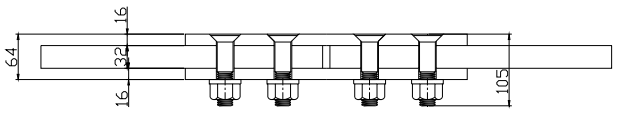

(c) CD-32M16M

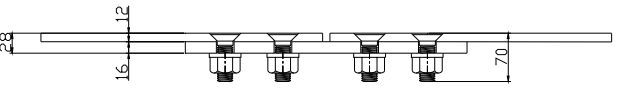

(d) CS-12S16M , CS-12M16M

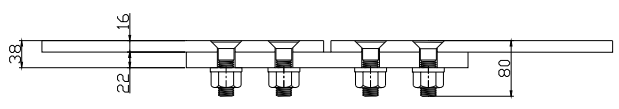

(e) CS-16M22M

Fig.9: Geometrical configurations of the Specimen for slippage test ( $\mathrm{mm}$ ) 
Table 2: List of specimens and experimental parameters

\begin{tabular}{|c|c|c|c|c|c|c|c|c|c|}
\hline & \multicolumn{2}{|c|}{ Base plate } & \multicolumn{2}{|c|}{ Splice plate } & \multirow{2}{*}{$\begin{array}{c}\text { Number of } \\
\text { the contact } \\
\text { surface }\end{array}$} & \multirow{2}{*}{$\begin{array}{c}\text { Slip to yield } \\
\text { resistance ratio } \\
\beta_{d}\end{array}$} & \multirow{2}{*}{$\begin{array}{c}\text { Slip to yield } \\
\text { resistance ratio } \\
\beta_{e}\end{array}$} & \multirow{2}{*}{$\begin{array}{l}\text { Number of the } \\
\text { specimen }\end{array}$} & \multirow{2}{*}{$\begin{array}{c}\text { Yield strength } \\
\text { of base plate } \\
\mathrm{Py}(\mathrm{kN})\end{array}$} \\
\hline & grade & $\mathrm{mm}$ & grade & $\mathrm{mm}$ & & & & & \\
\hline \multicolumn{10}{|c|}{ Countersunk head bolt } \\
\hline CD-12M12S & SM490 & 12 & SS400 & 12 & \multirow{4}{*}{ double } & 1.39 & 1.72 & 3 & 346 \\
\hline CD-12M12M & SM490 & 12 & SM490 & 12 & & 1.39 & 1.72 & 3 & 346 \\
\hline CD-16M12M & SM490 & 16 & SM490 & 12 & & 1.04 & 1.28 & 3 & 466 \\
\hline CD-32M16M & SM490 & 32 & SM490 & 16 & & 0.52 & 0.66 & 3 & 899 \\
\hline CS-12S16M & SS400 & 12 & SM490 & 16 & \multirow{3}{*}{ single } & 1.08 & 1.21 & 3 & 230 \\
\hline CS-12M16M & SM490 & 12 & SM490 & 16 & & 0.78 & 0.96 & 3 & 309 \\
\hline CS-16M22M & SM490 & 16 & SM490 & 22 & & 0.57 & 0.69 & 3 & 429 \\
\hline \multicolumn{10}{|c|}{ Hexagon head bolt } \\
\hline HD-12M12S & SM490 & 12 & SS400 & 12 & \multirow{4}{*}{ double } & 1.39 & 1.93 & 3 & 346 \\
\hline HD-12S12M & SM490 & 12 & SM490 & 12 & & 1.39 & 1.93 & 3 & 346 \\
\hline HD-16M12M & SM490 & 16 & SM490 & 12 & & 1.04 & 1.43 & 3 & 466 \\
\hline HD-32M16M & SM490 & 32 & SM490 & 16 & & 0.52 & 0.74 & 3 & 899 \\
\hline HS-12S16M & SS400 & 12 & SM490 & 16 & \multirow{3}{*}{ single } & 0.96 & 1.21 & 3 & 257 \\
\hline HS-12M16M & SM490 & 12 & SM490 & 16 & & 0.70 & 0.96 & 3 & 346 \\
\hline HS-16M22M & SM490 & 16 & SM490 & 22 & & 0.52 & 0.73 & 3 & 466 \\
\hline
\end{tabular}

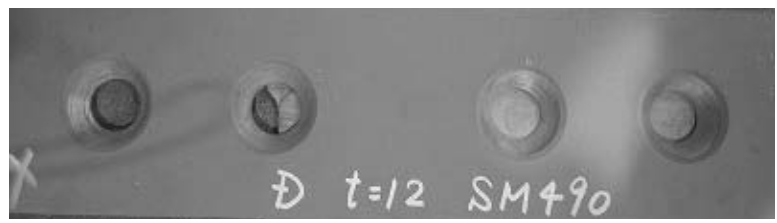

(a) surface of countersunk hole

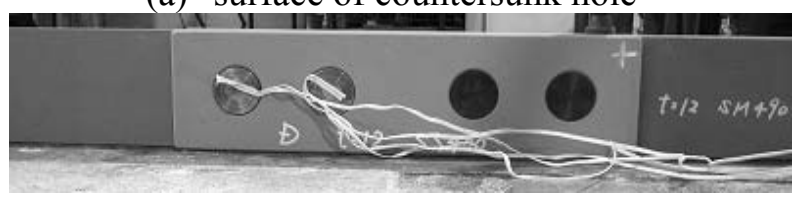

(b) After tightened of bolts

Pic.3: Overview of the Specimen

Table 3: Results of the material test

\begin{tabular}{|c|c|c|c|c|c|}
\hline \multirow{2}{*}{ Material } & Thickness & $\begin{array}{c}\text { Yield } \\
\text { strength }\end{array}$ & $\begin{array}{c}\text { Tensile } \\
\text { strength }\end{array}$ & $\begin{array}{c}\text { Elastic } \\
\text { modulus }\end{array}$ & \multirow{2}{*}{$\begin{array}{c}\text { Poïson's } \\
\text { ratio }\end{array}$} \\
\cline { 2 - 5 } & $\mathrm{mm}$ & $\mathrm{N} / \mathrm{mm}^{2}$ & $\mathrm{~N} / \mathrm{mm}^{2}$ & $\mathrm{~N} / \mathrm{mm}^{2}$ & \\
\hline SM490 & 32 & 338.2 & 500.5 & $2.07 \times 10^{5}$ & 0.28 \\
\hline SM490 & 22 & 344.0 & 533.6 & $2.11 \times 10^{5}$ & 0.29 \\
\hline SM490 & 16 & 350.5 & 526.2 & $2.10 \times 10^{5}$ & 0.29 \\
\hline SM490 & 12 & 347.0 & 516.5 & $2.09 \times 10^{5}$ & 0.29 \\
\hline SS400 & 12 & 275.8 & 434.5 & $2.09 \times 10^{5}$ & 0.29 \\
\hline
\end{tabular}

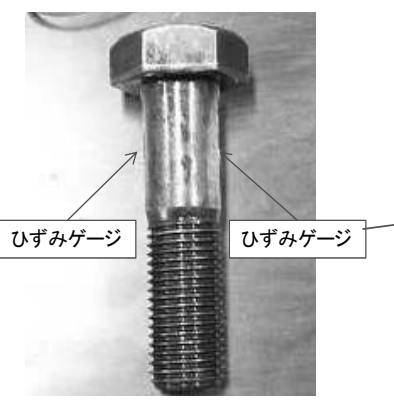

(a) Hexagon head

(b) Countersunk head measurement

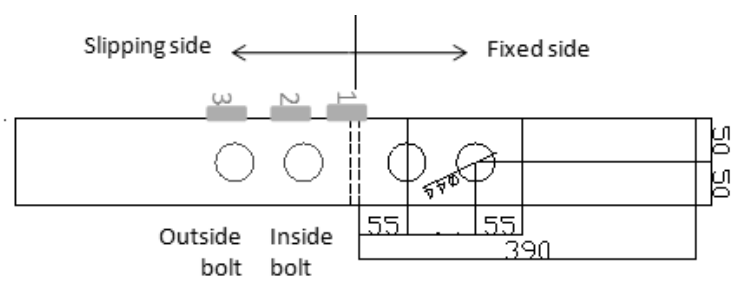

(a) Countersunk head bolt

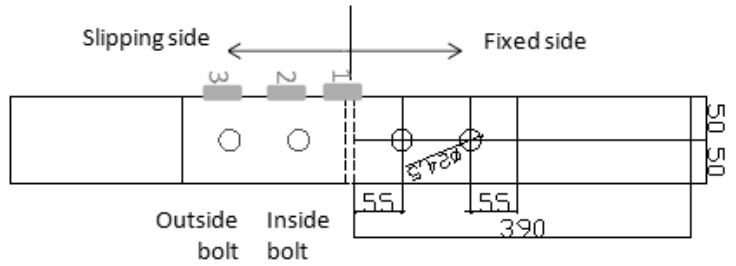

(b) Hexagon head bolt

Fig.10: Dimensions of the specimen and measured location of relative displacements

\subsection{Experimental Results and discussions}

\subsubsection{Definition of the slip coefficient}

Experimental results are summarized in Table.4. Each obtained slipping resistance force and slip coefficient are tabulated. The slip coefficient $\mu 1$ is the ratio of the slipping resistance force divided by the total bolt axial 
force before slippage test as shown in the equation (1),

$$
\mu_{1}=\frac{P}{m * n * N_{1}}
$$

$\mu 1$ : slip coefficient

$\mathrm{P}$ : slipping resistance force at $\delta 3=0.2 \mathrm{~mm}$

$(\mathrm{kN})$

$\mathrm{m}$ : number of the splice plate

$\mathrm{n}$ : number of the bolt

N1 : average of two bolts axial force before slippage test $(\mathrm{kN})$

The slip coefficient $\mu 0$ is the ratio of the slipping resistance force divided by design bolt axial force as shown in the equation (2),

$$
\mu_{0}=\frac{P}{m * n * N_{0}}
$$

N0 : design bolt axial force $(205 \mathrm{kN})$

The slip coefficient $\mu 2$ is the ratio of the slipping resistance force divided by total bolts axial force when slipping occurs as shown in the equation (3),

$$
\mu_{2}=\frac{P}{m * n * N_{2}}
$$

$\mathrm{N} 2$ : average bolt axial force at slip $(\mathrm{kN})$

\subsubsection{Effectiveness of the steel material grade}

In order to clarify the slip resistance under various steel grades (SS400, and SM490), it is compared with the slip coefficient of CD-12M12M and CD-12M12S as yielding type. Also CS-12M16M and CS-12S16M as slipping type are investigated.

As shown in Table.4, slip coefficient of CD-12M12M $(\mu 1=0.46)$ is approximately $2 \%$ higher than that of CD-12M12S $(\mu 1=0.45)$. In addition, CS-12M16M $(\mu 1=0.51)$ is also approximately $11 \%$ higher than that of CS12S16M $(\mu 1=0.46)$.

These results indicate that slip coefficients becomes higher by using high strength steel SM490 for the splice plate with countersunk bolt holes. The improvement of the slip coefficient for the slipping type by using higher strength steel is more effective than that of the yielding type.

\subsubsection{Slip to yield resistance ratio $\beta$ and number of the contact surface}

Fig. 11 shows the relationship between slip coefficient $\mu 1$ and slip to yield resistance ratio $\beta$ e. It is observed that slip coefficient $\mu 1$ has a tendency to get lower by increase of $\beta$ e regardless of bolt type, steel material grade, and number of the contact surface.

Maximum slip coefficient $\mu 1$ is $0.66(\mathrm{CD}-32 \mathrm{M} 16 \mathrm{M}) / 0.74(\mathrm{HD}-32 \mathrm{M} 16 \mathrm{M})$ for $\mathrm{CD} / \mathrm{HD}$ series respectively. These are both slipping type. Minimum slip coefficient $\mu 1$ is 0.45 (CD-12M12S) /0.48(HD-12M12S) for $\mathrm{CD} / \mathrm{HD}$ series respectively. These are both yielding type. It is summarized that slip coefficients $\mu 1$ for the countersunk head specimens are approximately $10 \%$ lower than those for hexagon head specimens in spite of number of the contact surface.

The reason is considered that the contact pressure of the joints with countersunk head reduce due to progress 
Table 4: Summary of experimental results

\begin{tabular}{|c|c|c|c|c|c|c|c|c|c|c|c|}
\hline \multirow[t]{2}{*}{ Specimen } & \multirow{2}{*}{ 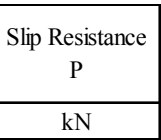 } & \multirow{2}{*}{$\begin{array}{c}\text { Axial force } \\
\text { before test } \\
\mathrm{N} 1\end{array}$} & \multirow{2}{*}{$\begin{array}{l}\text { Axial force at } \\
\text { slipping } \\
\mathrm{N} 2 \\
\mathrm{kN} \\
\end{array}$} & \multicolumn{2}{|c|}{$\begin{array}{l}\text { Slip coefficient } \\
\quad(\mathrm{P} / \mathrm{N} 1)\end{array}$} & \multicolumn{2}{|c|}{$\begin{array}{l}\text { Slip coefficient } \\
(\mathrm{P} / 205 \mathrm{kN})\end{array}$} & \multicolumn{2}{|c|}{$\begin{array}{l}\text { Slip coefficient } \\
\quad(\mathrm{P} / \mathrm{N} 2)\end{array}$} & \multicolumn{2}{|c|}{$\begin{array}{l}\text { decreasing rate of axial } \\
\text { force }\end{array}$} \\
\hline & & & & $\mu_{1}$ & Ave. & $\mu_{0}$ & Ave. & $\mu_{2}$ & Ave. & Ratio & Ave. \\
\hline \multicolumn{12}{|c|}{ Double shear series } \\
\hline \multirow{3}{*}{ CD-12M12S } & 364.79 & 208.97 & 186.96 & 0.44 & \multirow{3}{*}{0.45} & 0.44 & \multirow{3}{*}{0.45} & 0.49 & \multirow{3}{*}{0.50} & 0.89 & \multirow{3}{*}{$11.2 \%$} \\
\hline & 366.05 & 207.69 & 186.89 & 0.44 & & 0.45 & & 0.49 & & 0.90 & \\
\hline & 386.07 & 209.30 & 182.08 & 0.46 & & 0.47 & & 0.53 & & 0.87 & \\
\hline \multirow{3}{*}{ HD-12M12S } & 363.91 & 192.37 & 178.15 & 0.47 & \multirow{3}{*}{0.48} & 0.44 & \multirow{3}{*}{0.46} & 0.51 & & 0.93 & \\
\hline & 387.99 & 195.99 & 168.83 & 0.49 & & 0.47 & & 0.57 & 0.54 & 0.86 & $9.9 \%$ \\
\hline & 379.76 & 197.95 & 181.39 & 0.48 & & 0.46 & & 0.52 & & 0.92 & \\
\hline & dect & asing rate of & slip coefficien & $(C / H)$ & $6.2 \%$ & & $2.2 \%$ & & $7.4 \%$ & & \\
\hline & 384.51 & 209.20 & 189.91 & 0.46 & & 0.47 & & 0.51 & & 0.91 & \\
\hline CD-12M12M & 385.99 & 208.05 & 183.75 & 0.46 & 0.46 & 0.47 & 0.46 & 0.53 & 0.50 & 0.88 & $9.8 \%$ \\
\hline & 368.44 & 208.08 & 190.50 & 0.44 & & 0.45 & & 0.48 & & 0.92 & \\
\hline & 389.26 & 201.03 & 183.66 & 0.48 & & 0.47 & & 0.53 & & 0.91 & \\
\hline HD-12M12M & 378.49 & 202.23 & 186.43 & 0.47 & 0.48 & 0.46 & 0.47 & 0.51 & 0.52 & 0.92 & $8.2 \%$ \\
\hline & & invalid & & & & & & & & & \\
\hline & dect & asing rate of & slip coefficien & $(\mathrm{C} / \mathrm{H})$ & $4.2 \%$ & & $2.1 \%$ & & $2.7 \%$ & & \\
\hline & 422.93 & 210.67 & 191.31 & $\begin{array}{r}0.50 \\
\end{array}$ & & 0.52 & & 0.55 & & 0.91 & \\
\hline CD-16M12M & 460.29 & 214.18 & 192.07 & 0.54 & 0.53 & 0.56 & 0.55 & 0.60 & 0.59 & 0.90 & $10.2 \%$ \\
\hline & 474.37 & 211.39 & 187.74 & 0.56 & & 0.58 & & 0.63 & & 0.89 & \\
\hline & 469.89 & 198.80 & 181.42 & 0.59 & & 0.57 & & 0.65 & & 0.91 & \\
\hline HD-16M12M & 484.38 & 201.61 & 182.43 & 0.60 & 0.60 & 0.59 & 0.58 & 0.66 & 0.66 & 0.90 & $9.6 \%$ \\
\hline & 473.05 & 198.95 & 178.15 & 0.59 & & 0.58 & & 0.66 & & 0.90 & \\
\hline & dect & asing rate of & slip coefficien & $(\mathrm{C} / \mathrm{H})$ & $11.7 \%$ & & $5.2 \%$ & & $9.7 \%$ & & \\
\hline & |579.87 & 218.96 & 200.45 & 0.66 & & 0.71 & & 0.72 & & 0.92 & \\
\hline CD-32M16M & 593.38 & 220.53 & 202.19 & 0.67 & 0.66 & 0.72 & 0.72 & 0.73 & 0.72 & 0.92 & $8.4 \%$ \\
\hline & 588.19 & 228.85 & 209.69 & 0.64 & & 0.72 & & 0.70 & & 0.92 & \\
\hline & 594.56 & 202.13 & 187.59 & 0.74 & & 0.73 & & 0.79 & & 0.93 & \\
\hline HD-32M16M & & invalid & & & 0.74 & & 0.73 & & 0.79 & & $7.1 \%$ \\
\hline & 602.19 & 203.97 & 189.85 & 0.74 & & 0.73 & & 0.79 & & 0.93 & \\
\hline & dect & asing rate of & slip coefficien & $(\mathrm{C} / \mathrm{H})$ & $10.8 \%$ & & $1.4 \%$ & & $9.2 \%$ & & \\
\hline Single shear s & eries & & & & & & & & & & \\
\hline & & invalid & & & & & & & & & \\
\hline CS-12S16M & 195.20 & 216.53 & 171.96 & 0.45 & 0.46 & 0.48 & 0.48 & 0.57 & 0.58 & 0.79 & $20.6 \%$ \\
\hline & 198.72 & 211.42 & 167.76 & 0.47 & & 0.48 & & 0.59 & & 0.79 & \\
\hline & & invalid & & & & & & & & & \\
\hline HS-12S16M & 202.30 & 202.11 & 171.21 & 0.50 & 0.52 & 0.49 & 0.51 & 0.59 & 0.62 & 0.85 & $17.2 \%$ \\
\hline & 213.53 & 200.34 & 162.20 & 0.53 & & 0.52 & & 0.66 & & 0.81 & \\
\hline & dect & asing rate of & slip coefficien & $(\mathrm{C} / \mathrm{H})$ & $11.5 \%$ & & $5.9 \%$ & & $7.1 \%$ & & \\
\hline & 237.48 & 213.85 & 174.41 & 0.54 & & 0.58 & & 0.66 & & 0.82 & \\
\hline CS-12M16M & 224.49 & 228.46 & 188.73 & 0.49 & 0.51 & 0.55 & 0.56 & 0.59 & 0.62 & 0.83 & $17.6 \%$ \\
\hline & 223.31 & 218.53 & 181.55 & 0.51 & & 0.54 & & 0.61 & & 0.83 & \\
\hline & 234.17 & 214.29 & 181.69 & 0.55 & & 0.57 & & 0.64 & & 0.85 & \\
\hline HS-12M16M & 219.89 & 203.11 & 178.30 & 0.54 & 0.54 & 0.54 & 0.55 & 0.62 & 0.63 & 0.88 & $13.7 \%$ \\
\hline & & Invalla & & & & & 180 & & 120 & & \\
\hline & aect & & sip coejficlen & & $5.6 \%$ & & $-1.8 \%$ & & $1.5 \%$ & & \\
\hline CS-16M22M & 264.10 & \begin{tabular}{|l|}
215.49 \\
236.12
\end{tabular} & 182.31 & 0.61 & & 0.64 & & 0.12 & & 0.85 & \\
\hline & $\frac{252.404}{24725}$ & $\frac{230.12}{222.14}$ & 207.00 & 0.53 & & 0.02 & & 0.00 & & 0.89 & 12.910 \\
\hline & $247.23 \mid$ & $\mid 222.14$ & 196.00 & 0.56 & & 0.60 & & 0.63 & & 0.00 & \\
\hline $\mathrm{HS}-16 \mathrm{M} 22 \mathrm{M}$ & & invalid & & & 060 & 0.03 & & 0.08 & & & $\sin ^{2}$ \\
\hline & & invalid & & & 0.01 & & 0.05 & & 0.00 & & \\
\hline & dect & asing rate of & slip coefficien & $(\mathrm{C} / \mathrm{H})$ & $6.6 \%$ & & $1.6 \%$ & & $4.1 \%$ & & \\
\hline
\end{tabular}

of local yielding around the countersunk bolt holes by increasing applied tensile load.

Slip coefficients of the double shear series are higher than those of the single shear series regardless of type of the bolt head. This is caused by that the contact pressure of the single shear joints is lower than that of the double shear joints because of eccentric bending between the base plate and the splice plate.

Fig. 12 shows the relationship between slip coefficient $\mu 2$ and slip to yield resistance ratio $\beta \mathrm{e}$. It can be confirmed that the slip coefficients $\mu 2$ of all specimens are higher than the slip coefficients $\mu 1$.

It is also found that the variation of the slip coefficients $\mu 2$ under the same slip to yield resistance ratio $\beta$ is 
smaller compared with the variation of the slip coefficients $\mu 1$. Because the slip coefficients $\mu 2$ are evaluated by the slipping resistance force and total of bolt axial forces at slip occurrence, these values become higher and the variation becomes smaller by elimination of the bolt axial force decreasing during load transfer.

It is concluded from the experimental results that the slip strength of the joints with countersunk head bolts exceeds the design required slip strength which has specified in JSHB by the slip coefficient 0.45 .

\section{Conclusions}

This paper deals with the applicability of high strength bolted friction grip joints with countersunk head bolts for steel bridge structures which can finish the surface of the connection plate flat smoothly and prevent from functional depression due to corrosion. The main conclusions obtained are as follows,

(1) In order to clarify distribution of the contact pressure on the contact surface of the joints with countersunk heads, the FEA was carried out varying the angle of countersunk head. It has concluded that the most desirable angle of the countersunk head is 90 degrees from the viewpoint of distribution of the contact pressure and stress concentration of the bolt.

(2) In the cases of CD series, the FEA results indicate that high contact pressure over yield strength occurs around the countersunk edge of the bolt hole and the distributing area is small comparing with HD series.

(3) In order to clarify the behavior of friction joints with countersunk head bolts, the standard slippage test were executed considering variation of plate thickness and the yielding strength of the base and splice plates.

(4) It has concluded from the experimental results that the slip strength of the joints with countersunk head bolts exceeds the design slip strength specified in JSHB calculated by the slip coefficient 0.45 and that its slip strength is about only $10 \%$ lower than that with normal head bolts. It is caused by that the contact pressure of the joints with countersunk head reduce due to progress of local yielding around the bolt holes as increasing applied tensile load.

(5) In order to apply such joints to practical joints of bridge members, further researches on applicability of the over-sized holes and multiple arrangements of countersunk bolts and so on are should be required.

1) SIMULIA:Abaqus Analysis User's Manual,Vol.1-5

\section{References}

2) Japan road association: Specifications for highway bridges, Part2 steel bridges, 2012 (in Japanese)

3) A Monta, Tanihira T.; Experimental Study on the Shape Improvement and application of High Tension Countersunk Head Bolts in Friction Grip Joints, JSSC Journal of Constructional Steel, Vol.6, pp.65-76, 1992 (in Japanese)

4) Architectural Institute of Japan: Recommendation for Design of Connections in Steel Structures, 2006 (in Japanese) 